\title{
A research on fuelling a truck diesel engine with hydrogen
}

\author{
Nikolaos Cristian Nutu, ${ }^{1,}$, Constantin $\mathrm{Pana}^{2}$, Niculae Negurescu ${ }^{2}$, Alexandru Cernat ${ }^{2}$, Dinu \\ Fuiorescu $^{2}$, and Ionel Mirica ${ }^{2}$ \\ ${ }^{1}$ University Politehnica of Bucharest, Automotive Engineering Department, Bucharest, Romania \\ ${ }^{2}$ University Politehnica of Bucharest, Termothechnics, Engines, Thermal Equipments, and Refrigeration \\ Instalations Department, Bucharest, Romania
}

\begin{abstract}
The paper presents experimental and theoretical investigations results of a truck diesel engine fuelled with diesel fuel and hydrogen by diesel-gas method. The purpose of the paper is to reduce the level of the nitrogen oxides emission level and to improve the overall performances of the engine. The use of hydrogen represents a suitable method to reduce the classic fuels consumption, maintaining the energetic performances of the engine. The test bed situated in the Thermotechnics, Engines, Thermal Equipments and Refrigeration Instalations Department of University Politechnica of Bucharest was adapted for hydrogen fuelling of the truck diesel engine. The engine used for investigations is a turbocharged 10.21 truck diesel engine which run at $1450 \mathrm{rpm}$ and $40 \%$ engine load. By hydrogen fuelling if the investigated diesel engine a decrease has been achieved in the nitrogen oxides emission level and in the smoke emission level. Also the break energetic specific consumption decreased compared to the standard diesel engine. The theoretical investigations presented in tha paper are based on a semi-empirical corellation, used to simulate the nitrogen monoxide emission formation. The results of the experimental investigations confirm de viability of hydrogen as an alternative fuel for the diesel engine.
\end{abstract}

\section{Introduction}

The element hydrogen is greatly widespread in the universe, forming over $90 \%$ of the universe [1]. On the earth, hydrogen is found very little in the upper layers of the atmosphere and in very large quantities combined with oxygen and thus forming water. One $\mathrm{km}^{3}$ of water contains 113 million tons of hydrogen [1]. Some of important properties of hydrogen are presented in the table 1, along with those of diesel fuel. 
Table 1. The hydrogen properties [1].

\begin{tabular}{|l|l|l|}
\hline Property [] & Diesel fuel & Hydrogen \\
\hline Molar mass [kg/kmol] & 226.44 & 2.016 \\
\hline LHV [kJ/kg] & 41855 & 119600 \\
\hline $\begin{array}{l}\text { Autoignition } \\
\left.\text { temperature [ }{ }^{\circ}\right]\end{array}$ & $200 \ldots .220$ & $565.56 \ldots 582.22$ \\
\hline Octane number [-] & - & $>130$ \\
\hline Density [kg/m $\left.{ }^{3}\right]$ & $800-840$ & 0.089 \\
\hline Ignition energy [mJ] & - & 0.02 \\
\hline
\end{tabular}

It is complicated to provide hydrogen as unique fuel of compression ignition engines because the compression ratio being high the fuel-mixture has an uncontrolled tendency to ignite due to the very narrow range of usable dosages. This combined with low hydrogen ignition energy can result in elevated pressure rise rates and increased cycle to cycle dispersion. A method of controlling the combustion process that produces very good results is that hydrogen is used as an additive fuel, introduced in the form of vapors in the engine intake manifold. This fuelling procedure is also called the diesel gas method, whereby the air-hydrogen mixture formed in the intake manifold is admitted into the cylinders and ignited by the flame appeared in the previously injected diesel fuel sprays. It is therefore necessary to equip the engine with a separate gas fuel supply system capable of being permanently correlated with the conventional diesel fuel system.

Varde et al. in [2], studied the effects of hydrogen fuelling by introducing hydrogen into the intake manifold of a diesel engine. The main objective of this research was to reduce the particulate emission level in exhaust gases using hydrogen as addition fuel. Hydrogen substitution was equal to $10 \%$ (as a percentage of energy) and reduced the level of smoke emission at partial load. However, at the nominal load the reduction of the smoke emission level was more modest, most likely due to the reduced amount of air available in the cylinder. It has also been found that reduced hydrogen rates have had side effects on engine efficiency, but increasing the percentage of hydrogen rate notable improvements in efficiency has been obtained.

Haroun A.K. Shahad and Nabeel Abdul-Hadi conducted an experiment on a diesel engine with hydrogen injection in the intake, observing an increase in thermal efficiency of $\sim 40 \%$ at engine load of $60-80 \%$. At higher loads the thermal efficiency decreased dramatically due to incomplete combustion, the excess air ratio being low [3]. However, even the brake thermal efficiency increased, the NOx emissions increased with the increasing degree of substitution of diesel fuel with hydrogen at high engine loads, similar results were found in [4].

The paper [5] presents the effects of hydrogen addition on the energy and pollution performances of a diesel engine fueled with diesel fuel as a pilot and hydrogen-methane as a dual fuel. The effect of gaseous fuel on the maximum pressure inside the cylinder and on the heat release rate is relatively low at low and medium loads [5]. At high loads, however, the addition of gaseous fuel contributes to increasing the efficiency of the combustion process and increasing the maximum pressure inside the cylinder. Also the increase in the amount of hydrogen has led to an increase in the maximum pressure. At low and medium engine loads the authors determined that the maximum in cylinder pressure drops with the increase in the amount of gaseous fuel injected into the intake manifold (hydrogen + 
methane). At high engine loads, the cylinder pressure increased due to increased temperature and intensified burning process, with a relatively high flame speed in the airhydrogen-methane mixture [5]. Also, the burning process has become unstable and difficult to control [5]. This is confirmed by Gatts et. al. [6], which suggests that the efficiency of the combustion is related with the engine load and that hydrogen should be added at higher loads in order to improve the engines's brake thermal efficiency [6]. The nitrogen oxides emission level presented in the paper [5] increased in the case of fuelling with hydrogen compared to the classic diesel fuel supply, especially for medium and large engine loads. One reason that could explain the increased NOx level is the increase in the global temperature of the combustion process [5]. In the case of running at low engine loads, the hydrogen fueled engine produces lower levels of nitrogen oxides, but with increasing hydrogen quantity, the emission level begins to rise [5]. The authors also found that in the case of fuelling with hydrogen, the nitrogen dioxide emission is present in large quantities in the exhaust gases of the engine, which is very dangerous for humans and the environment, but it is beneficial for reducing the level of smoke emission, the $\mathrm{NO}_{2}$ emission playing an essential role of a very good soot oxidant [5]. This is confirmed in the paper [7]. The level of unburned hydrocarbon emissions increased for almost all cases where the engine was fueled with gaseous fuel, except for hydrogen. A cause of the increase in the emission level could be the loss of a gaseous fuel quantity during the overlapping period of the valves [5], [8]. The paper [9] explains the increase in the level of unburned hydrocarbon emissions by lowering the local excess air ratio when the dual fuel is used.

In [10] by supplying hydrogen with diesel fuel, $\mathrm{CO}, \mathrm{HC}$ and smoke emissions decreased due to improved combustion, but a slight increase in $\mathrm{CO}_{2}$ emissions is observed [10].

This paper presents experimental and theoretical investigations results of a truck diesel engine fuelled with diesel fuel and hydrogen by diesel-gas method. The purpose of the paper is to reduce the level of the nitrogen oxides emission level and to improve the overall performances of the engine. The engine used for investigations is a turbocharged 10.21 truck diesel engine and the working regimen was $1450 \mathrm{rpm}$ and $40 \%$ engine load.

\section{Material and method}

\subsection{The test bed description}

For this paper the theoretical and experimental study were carried out having as a material support an experimental test bed equipped with a 10.21 truck compression ignition engine. The engine main specifications are shown in the table 2 .

Table 2. The main specifications of the D2156MTN8 engine.

\begin{tabular}{|c|c|}
\hline Number of cylinders & 6 \\
\hline Bore [mm] & 121 \\
\hline Stroke [mm] & 150 \\
\hline Displacement [l] & 10.34 \\
\hline Compression ratio & 17 \\
\hline Rated power [kW] & 188 \\
\hline Maximum torque [Nm] & 900 \\
\hline Admision type & turbocharged \\
\hline
\end{tabular}

The laboratory equipments are: a Hoffman eddy current dynamometer, an AVL data aquisition system, a Kistler piezoelectric pressure transducer, an Allicat Stiintific mass 
flowmeter, a Meriam volume flowmeter, an AVL Dicom gas analyser and opacimeter, multiple thermocouples and thermoresistances for temperature measuring and a gravimetric fuel consumption measuring system to determine the diesel fuel consumption.

\subsection{The nitrogen monoxide emission theoretical model}

As presented in the abstract, the nitrogen monoxide emission level was computed with an semi-emprical mathematical equation and compared with measured results. The mathematical model which describes the NO emission formation is given by the formula 1 [11].

$$
|N O|=\mathrm{C}_{1} *(\lambda-0.89)^{2.11} * \mathrm{n}^{-0.39} * Q_{z}^{2.49} * m_{a}^{-5.01} *\left(\int_{0}^{Q_{z}} T^{11} p^{9} d Q_{z}\right)^{0.28}[\mathrm{ppm}]
$$

$\lambda$ - exces air ratio;

$\mathrm{n}[\mathrm{rot} / \mathrm{s}]$ - the engine speed;

$\mathrm{Qz}[\mathrm{kJ} /$ cycle $]$ - the heat released;

$\mathrm{m}_{\mathrm{a}}[\mathrm{g}]$ - fresh charge mass;

$\mathrm{T}[\mathrm{K}]$ - the temperature;

$\mathrm{p}[\mathrm{bar}]$ - the pressure;

$\mathrm{C}_{1}$ - calibration constant.

The calibration constant used in this model has the value of 1 . Because the combustion process period can be divided in small intervals for the simulation purpose, the integral presented in the equation (1) can be replaced with a sum of pressure, temperature and the average rate of heat released [1].

$$
\int_{0}^{Q_{z}} T^{11} p^{9} d Q_{z}=\sum T_{m}^{11} * p^{9} * \Delta Q_{z}
$$

\subsection{The working regimen and the method description}

At the begining, when the experimental investigation started the engine was fuelled with diesel fuel. The purpose was to determine the standard regimen in order to maintain it as a reference. So the first investigated point was at $1450 \mathrm{rpm}$ and $40 \%$ engine load, having diesel fuel as a fuel. After the reference was created the diesel fuel was partially substituted with hydrogen by introducing it in its gaseous aggregation state in the intake manifold. The main goal was to maintain the engine performances at the same level like in the reference case and to decrease the pollutant emissions and the specific fuel consumption. This was accomplished by decreasing the diesel fuel quantity and adding hydrogen. The energetic diesel fuel substitution ratio with hydrogen is given by :

$$
x_{c}=\frac{m_{H 2} H_{i_{H 2}}}{m_{H 2} H_{i_{H 2}}+m_{\text {dieselfuel }} H_{i_{\text {dieselfuel }}}}
$$

$m_{H 2}$ the hydrogen quantity;

$m_{\text {dieselfuel }}$-the diesel fuel quantity;

$\mathrm{H}_{\mathrm{i}}$ - the lower heating value. 4.81].

The energetic diesel fuel substitution ratio with hydrogen was situated between [1.14- 


\section{Results and discussions}

\subsection{The maximum in cylinder pressure and the maximum rate of pressure rise}

Because the diesel fuel substitution rate with hydrogen was relatively low, a good control over the combustion process was achieved so the maximum in cylinder pressure and the maximum rate of pressure rise were maintained at aproximatelly the same level like in the case of fuelling only with diesel fuel. The maximum pressure has a slightly increasing trend with increasing degree of substitution but the maximum deviation is only 1 bar. The figures 1 and 2 presents the maximum in cylinder pressure and the maximum rate of pressure rise, having on $\mathrm{X}$ axis the degree of substitution $\mathrm{x}_{\mathrm{c}}$.

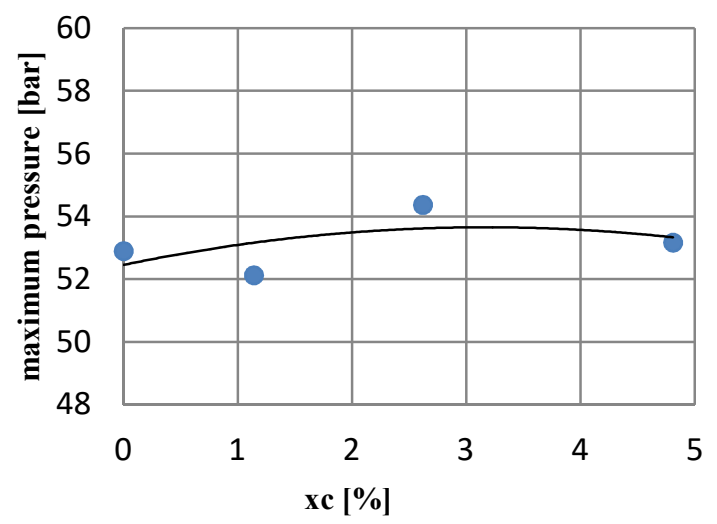

Fig . 1. The maximum in cylinder pressure.

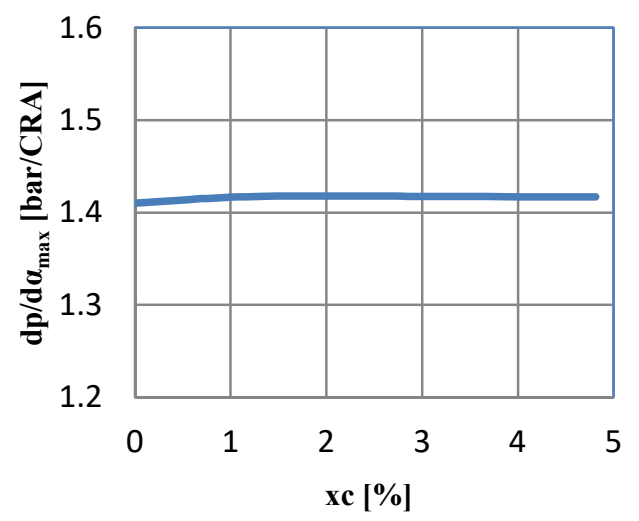

Fig. 2. The maximum rate of pressure rise.

\subsection{The nitrogen oxides emission level}

The measured nitrogen oxides emission level decreased for all the degrees of substitution of diesel fuel with hydrogen. An explanation for this phenomenon could be the richer local mixture in the case of fuelling with hidrogen. Also the mixture increasing degree of homogeneity tends to decrease the global temperature. The figures $3,4,5,6,7$ presents the $\mathrm{NO}_{\mathrm{x}}$ emission level for all the investigated cases. In the figure 3 is presented comparatively 
the measured and computed level. It can be seen that the semi-empirical equation predicts a lower level in the case of fuelling with hydrogen. The reason may be the fact that the equation predicts only the formation of $\mathrm{NO}$ and according to [5] when hydrogen is used as an additive fuel inside the cylinder is forming large quantities of $\mathrm{NO}_{2}$, which represents a good catalyst for the soot emission [5]. The figures 4, 5, 6, 7 presents the forming laws of NO over the in cylinder temperature. The temperature is obtained by processing the pressure diagrams. It can be also observed that the maximum level of the NO emission is obtained at a short time after the moment when the maximum temperature is reached and the NO emission start its forming process in the first stages of combustion, in the preformed mixtures combustion period.

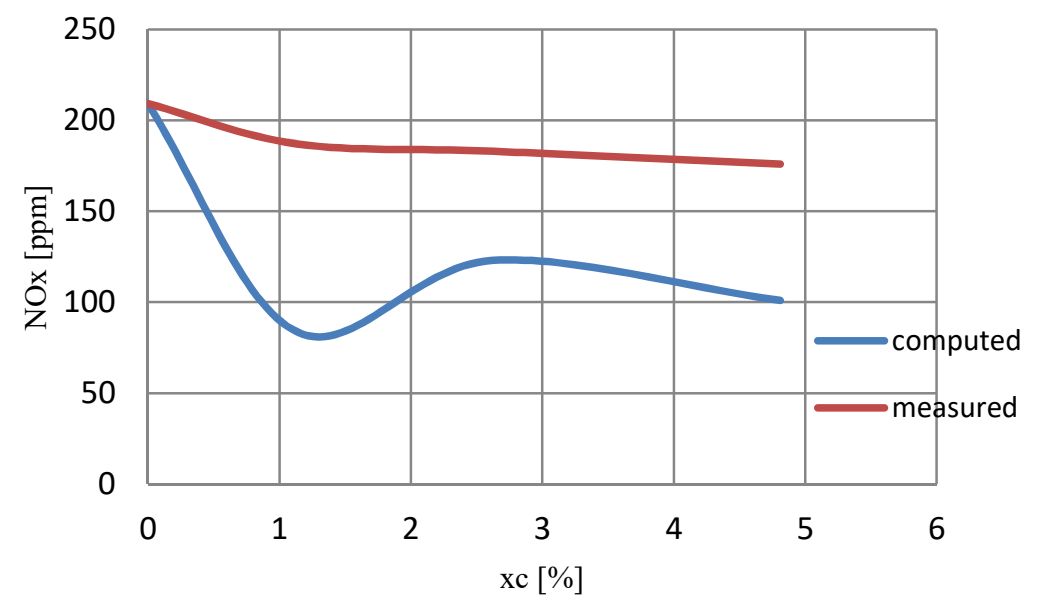

Fig. 3. The measured and computed nitrogen oxides emission level versus the degree of substitution.

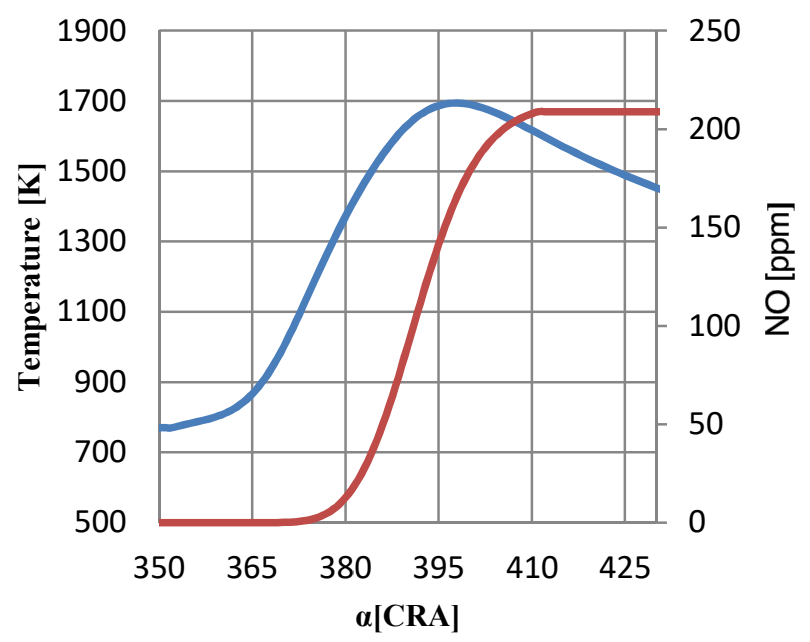

Fig. 4. The computed temperature and NO forming law for the case of $x_{c}=0$. 


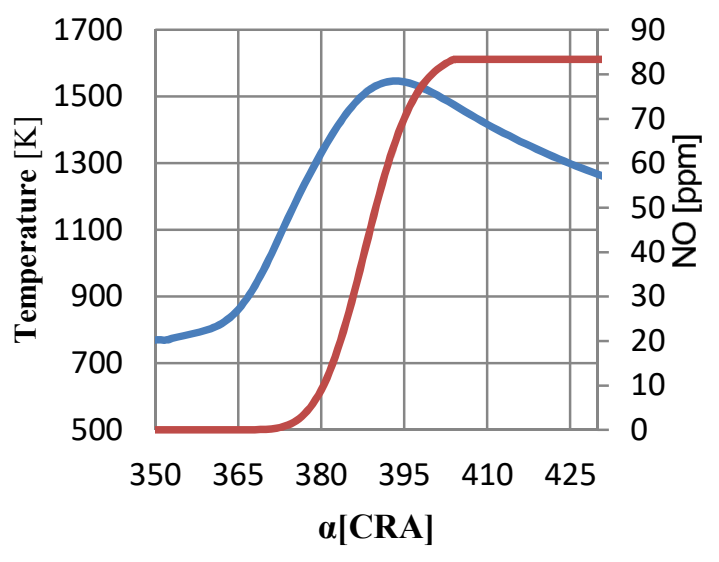

Fig. 5. The computed temperature and NO forming law for the case of $x_{c}=1.14$.

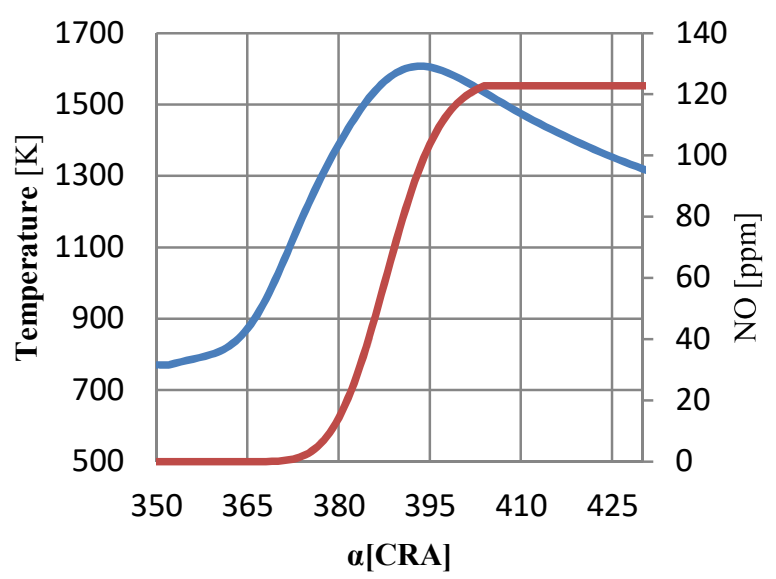

Fig. 6. The computed temperature and NO forming law for the case of $x_{c}=2.62$.

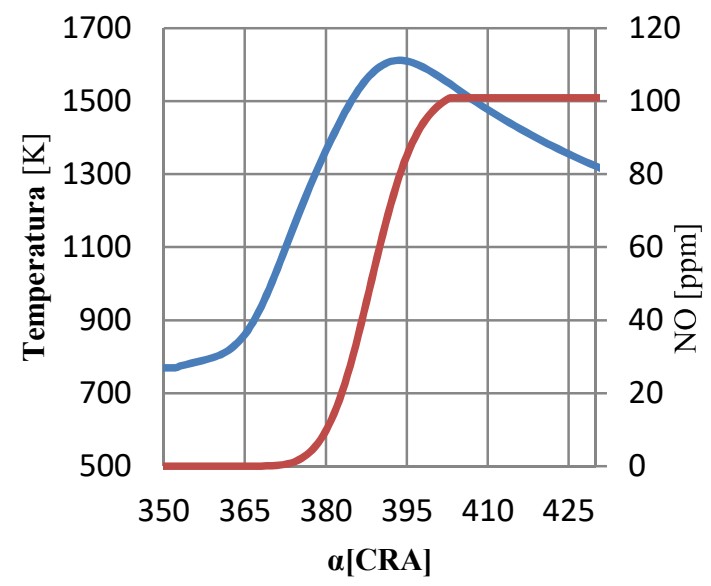

Fig. 7. The computed temperature and NO forming law for the case of $x_{c}=4.81$. 


\subsection{The smoke emission level}

The smoke emission level decreased for all the cases when the engine was fueled with hydrogen because when the gaseous fuel is present inside the combustion chamber the number of carbon atoms is lower, the burning rate of diffusive mixtures decreases and according to [5] the nitrogen dioxides emission represents a catalyst for the soot emission. The smoke emission is presented in the figure 8 , evaluated by the exhaust gases opacity.

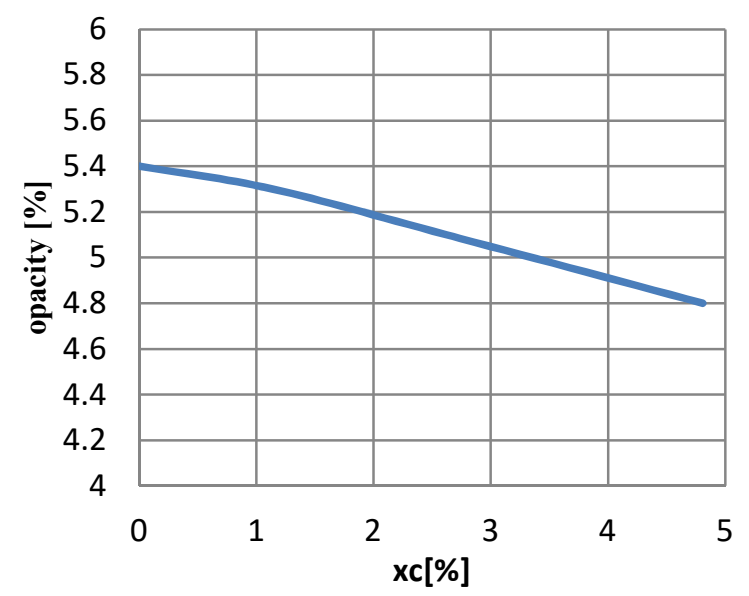

Fig. 8. The smoke emission level.

\subsection{The energetic specific fuel consumption}

The energetic specific fuel consumption decreased for all the cases of fuelling with hydrogen, with its lowest level at the degree of substitution $\mathrm{x}_{\mathrm{c}}=1.14$, because in the presence hydrogen in the combustion chamber the combustion process intensifies and become more efficient. The figure 9 presents the energetic specific fuel consumption.

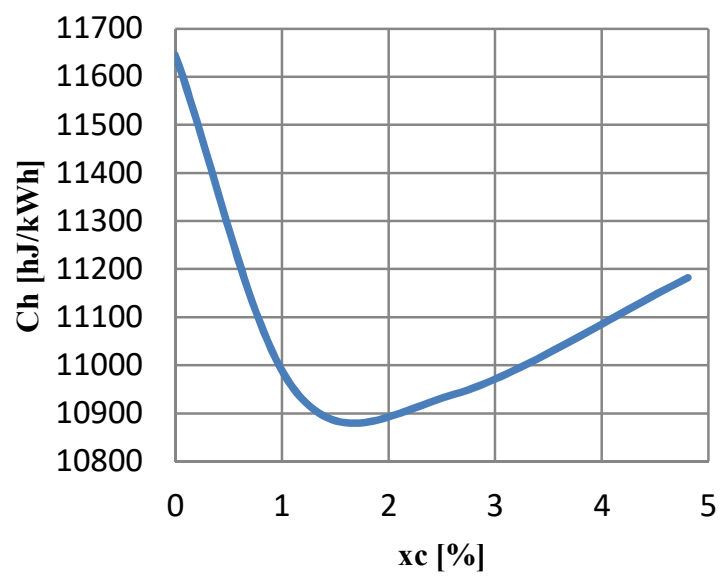

Fig. 9. The energetic specific fuel consumption. 


\section{Conclusions}

- The maximum in cylinder pressure and the maximum rate of pressure rise were maintained at aproximatelly the same level like in the case of fuelling only with diesel fuel. The maximum pressure has a slightly increasing trend with increasing degree of substitution but the maximum deviation is only 1 bar.

- In the case of hydrogen fuelling the nitrogen oxides emission level decreased.

- The smoke emission level decreased for all the cases when the engine was fueled with hydrogen with a maximum of $11 \%$ compared with the diesel fuel case.

- The energetic specific fuel consumption decreased for all the cases of fuelling with hydrogen, with its lowest level at the degree of substitution $\mathrm{x}_{\mathrm{c}}=1.14$.

The authors would like to express special thanks to AVL List GmbH Graz, Austria, for offering the opportunity to use the research equipments. This work has been funded by the Romanian Ministery of Research and Innovation, CCCDI - UEFISCDI, grant PN-III-P1-1.2-PCCDI-2017-0404 / $31 \mathrm{PCCDI} / 2018$.

\section{References}

1. M.G. Popa, N. Negurescu, C. Pana, Motoare Diesel. Procese, MatrixRom, Bucharest, (2003).

2. K.S. Varde, G.A. Frame (1983), Hydrogen aspiration in a direct injection type diesel engine-its effects on smoke and other engine performance parameters, Int J Hydr Energ, 159-179, (1983).

3. A. K. Shahad Haroun, A.H. Nabeel, Experimental Investigation of the Effect of Hydrogen Manifold Injection on the Performance of Compression Ignition Engines, World Academy of Science, Engineering and Technology 76, (2011).

4. W. B. Santosoa, R. A. Bakara, A. Nurb, Combustion characteristics of diesel-hydrogen dual fuel engine at low load, Energy Procedia, 32, (2013).

5. J. H. Zhou, C. S. Cheung, C. W. Leung, Combustion and Emission of a Compression Ignition Engine Fueled with Diesel and Hydrogen-Methane Mixture, World Academy of Science, Engineering and Technology International Journal of Mechanical, Industrial Science and Engineering 7, (2013)

6. T. Gatts, H. Li, C Liew, S. Liu, T. Spencer, T. Wayne, et al., An experimental investigation of H2 emissions of a 2004 heavy-duty diesel engine supplemented with H2, Int J Hydrogen Energ, 35, (2010).

7. S.Y. Liu, H.L. Li, T. Gatts, C. Liew, S . Wayne, G. Thompson, et al., An Investigation Of No2 Emissions From a Heavy-Duty Diesel Engine Fumigated with H2 and Natural Gas, Combust Sci Technol., 184, (2012).

8. T. Gatts, S. Liu, C . Liew, B. Ralston, C. Bell, H. Li, An experimental investigation of incomplete combustion of gaseous fuels of a heavy-duty diesel engine supplemented with hydrogen and natural gas, Int JHydrog Energy, (2012).

9. B. Sahoo, N. Sahoo, U. Saha, Effect of engine parameters and type of gaseous fuel on the performance of dual-fuel gas diesel engines - A critical review, Renewable and sustainable Energy Reviews, 13, (2009).

10. M. Talibi, P. Hellier, R. Balachandran, N. Nicos Ladommatos, Effect of hydrogen-diesel fuel cocombustion on exhaust emissions with verification using an in-cylinder gas sampling technique, International journal of hydrogen energy, 39, (2014).

11. G. Pădure, M. Pădure, Mecanisme ale formarii oxizilor de azot in motorul cu ardere interna, Zilele Academice Timisene editia, 8, (2001). 